\title{
A crônica como um espaço itinerante da cidade
}

\author{
Jeana Laura da Cunha Santos
}

\section{SciELO Books / SciELO Livros / SciELO Libros}

SANTOS, JLC. A crônica como um espaço itinerante da cidade. In: TRAVANCAS, I., and NOGUEIRA, SG., orgs. Antropologia da comunicação de massa [online]. Campina Grande: EDUEPB, 2016. Paradigmas da Comunicação collection, pp. 95-111. ISBN 978-85-7879-332-6.

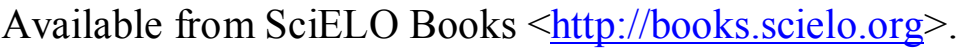

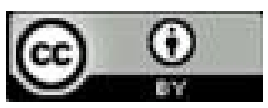

All the contents of this work, except where otherwise noted, is licensed under a Creative Commons Attribution 4.0 International license.

Todo o conteúdo deste trabalho, exceto quando houver ressalva, é publicado sob a licença Creative Commons Atribição 4.0.

Todo el contenido de esta obra, excepto donde se indique lo contrario, está bajo licencia de la licencia $\underline{\text { Creative }}$ Commons Reconocimento 4.0. 


\title{
A crônica como um espaço itinerante da cidade
}

\author{
Jeana Laura da Cunha Santos
}

\section{Introdução}

É no limiar entre dois tempos que duas experiências antagônicas, porém complementares, convivem lado a lado. Nestas zonas cinzentas, em que o novo não está completamente delineado e nem o passado é totalmente descartado que podemos depurar os sentidos e produzir quiçá uma reflexão teórica isenta de determinismos. Eis a dialética dos períodos de transição, onde o velho e o novo convivem lado a lado.

O presente trabalho procura tocar a beirada de dois tempos (a virada do século XIX para o XX) no espaço de um Rio de Janeiro constituído de passagens: entre o escravismo e a mão-deobra assalariada, entre a manufatura e o trabalho industrial, entre a Monarquia e a República, entre a escritura sacralizada do livro e a escritura mecanizada dos jornais.

Ao se atar estas pontas temporais, acaba-se por se debruçar também sobre o espaço em suas zonas fronteiriças. Nada mais emblemático desta passagem do que a transposição da zona 
domesticada da casa para a zona ignóbil da rua. Ir para a rua nos começos do século XX no Rio de Janeiro era feito com um misto de medo e prazer, o que não era prerrogativa apenas da cidade brasileira, uma vez que Walter Benjamin (1994) também se debruçaria sobre o fenômeno na sua análise da ocupação das ruas de Paris, e da consolidação da flânerie como novo modelo do habitante da cidade, aproximando o tipo do jornalista que transforma os muros em escrivaninhas, as bancas de jornal em bibliotecas e os terraços, a sacada de onde observa o ambiente.

Domesticar a ameaça subscrita na cidade era o imperativo e isso fica evidente na construção de espaços intermediários (nem tão a casa e nem tão a rua) na arquitetura da cidade. Se em Paris as galerias (que Benjamin definiria como um mundo em miniatura, com seus caminhos cobertos de vidro e revestidos de mármore e por onde se estende os mais elegantes estabelecimentos comerciais) cumpriam essa função de apaziguar o medo da rua, não seria outro o propósito da varanda no contexto brasileiro, definida por Saint-Hilaire (apud DAMATTA, 1987, p.56), europeu que visitou o Brasil em 1816 e 1822, como uma galeria sustentada por colunas de madeira que se prolonga na frente da casa e onde a gente abastada contempla a rua ao abrigo da chuva e do sol.

A arquitetura do texto também sofreria modificações. Um gênero literário do século XIX, resgatado por Benjamin, é a "literatura panorâmica". Dentro deste gênero, havia os fascículos em formato de bolso chamados de "fisiologias", que se ocupavam da descrição de tipos humanos que circulavam nas feiras de Paris. Mais tarde, dedicar-se-iam à consagração da cidade, perfilando suas ruas, seus panoramas, tudo para tornar aprazível a ameaça do outro estranho e do espaço "estrangeiro" da rua.

E se em Paris eram os fisiologistas que adquiriam status, aqui no Brasil, a crônica surgiria para aplacar os sentidos e se configurar 
como uma escritura moderna, calcada no modelo de fragmentação que abandona a casa do livro para se sagrar no veículo móvel, urbano e volátil do jornal.

E é essa passagem que nos interessa. Traçar uma fisiologia da crônica nos assuntos que documenta, já que tem os olhos voltados para as mínimas histórias que se engendram na cidade, e também enquanto uma narrativa urbana que alegoriza na sua própria forma (fragmentada, efêmera, distraída) a experiência moderna do habitante da cidade. Ao dissecá-la, pensar também no papel destes primeiros escribas (os jornalistas) que abandonaram a casa segura, canônica, domesticada da palavra livresca para se aventurar, enquanto flâneurs, no olho da rua.

Habitar as ruas é, então, tarefa do jornalista. No Brasil, a crônica seria o gênero inaugurador que retrataria o fluxo de sujeitos e fatos pelas ruas da cidade. A crônica abandonaria a casa da palavra para se deixar ir, volúvel e volátil, para o coração das ruas.

\section{Eis a origem da crônica}

Analisar a crônica enquanto um texto produzido na e sobre a cidade em trânsito é vê-la como uma narrativa urbana dentro de uma antropologia que pensa o movimento. Porque a crônica conserva em si, desde o tempo de sua gênese até os dias de hoje, os resíduos produzidos pela cidade que se moderniza. A fragmentação do olhar do homem moderno, sua necessidade de adaptar-se à aceleração da vida na cidade é sentido pelo transeunte na multidão. Forja-se uma coletividade que habita as ruas. Habitar as ruas é, então, tarefa do cronista. Se o livro é a alegoria do interior burguês, o jornal representa o fluxo de sujeitos e fatos pelas ruas da cidade em movimento. A crônica media esses dois espaços, reproduzindo o retrato de um tempo em 
que havia uma propensão do olhar para se deslocar do mundo fechado dos interiores burgueses para o mundo aberto das ruas em ebulição.

Escrita tipicamente brasileira, nela é possível detectar tanto na sua forma como nos assuntos que documenta "todo lo que en una ciudad puede ser visto flotando en su superfície” (DELGADO, 1999, p.26). Não é gratuito o fato de ter seus inícios em um Rio de Janeiro cujo traçado e formas de vida convergiam para o que se poderia definir como metrópole, em que pesem as contradições inerentes de um tempo marcado pelos descompassos políticos e sociais da virada do século XIX para o XX.

Traduzindo em si tais traços ambíguos dos momentos de transição, a crônica nasce imprecisa, volúvel, descartável, sem marco inicial, como ironizaria Machado de Assis, um de seus fiéis representantes na literatura nacional e um de seus grandes entusiastas:

Não posso dizer positivamente em que ano nasceu a crônica; mas há toda a probabilidade de crer que é coletânea das primeiras duas vizinhas. Essas vizinhas, entre o jantar e a merenda, sentaram-se à porta para debicar os sucessos do dia. Provavelmente começaram a lastimar-se do calor. Uma dizia que não pudera comer ao jantar, outra que tinha a camisa mais ensopada do que as ervas que comera. Passar das ervas às plantações do morador fronteiro, e logo às tropelias amatórias do dito morador, e ao resto, era a coisa mais fácil, natural e possível do mundo. Eis a origem da crônica. (FOLHA DE S. PAULO, 1994, p.13-15).

Marlyse Meyer (apud CANDIDO, 1992, p.93-113) ressalta a dificuldade de se precisar com exatidão o nascimento do gênero. Segundo ela, nos começos do século XIX, le feuilleton designava o rodapé da primeira página dos jornais, espaço destinado ao 
entretenimento e onde valia tudo: contar piadas, propor charadas, oferecer receitas... De espaço vale-tudo, passa, em finais de 1830, a publicar ficção em fatias, com enorme retorno financeiro para os jornais. Mas é no corpo interno do Jornal do Commércio, sob a rubrica de Variedade, que, em fins de 1830, passa-se a publicar aquilo que viria a dar na crônica: conteúdos variados, matérias traduzidas, resenhas, ficções curtas, poesias, lista de traduções etc. O romance-folhetim, "avô de todas as nossas novelas", continuaria a ocupar o rodapé da página um. Em ambos os casos, folhetim-variedade ou romance-folhetim, alguns escritores, ao terem que traduzir ou escrever a toque de caixa pelo novo imperativo da velocidade do meio jornal, transpuseram esse modo de escrita para o seu posterior texto de ficção, o que comprova a simbiose estabelecida nesse momento de transição, via folhetim ou crônica, entre a literatura e o jornalismo.

Segundo a autora, ao adotar um tom ligeiro, miúdo, da fala cotidiana, a crônica passou a incorporar também um toque de humor, libertando-se, enfim, do folhetim e passando a ter vida própria, sendo esse um momento crucial para o seu amadurecimento.

A crônica foi, então, a forma oportuna de passagem entre a literatura e o jornalismo, subscrevendo um novo estilo, contaminado pelo enquadramento fragmentário da diagramação das folhas, pela pressão dos horários, pela velocidade da própria movimentação das rotativas e em sincronia com os assuntos gerados pelas ruas de uma cidade cujo protagonista era sem dúvida o movimento.

A crônica alegoriza assim o espaço itinerante, em movimento, subscrito nas cidades. Ao revisar topografias sobre a mobilidade nas cidades, Delgado alude aos espaços transversais, cuja função seria o de transpassar, cruzar, intersectar outros territórios. "En los espacios transversales toda acción se plantearía como un a través de. No es que en ellos se produzca una travesía, sino que son la travesía en 
si, cualquier travesía. No son nada que no sea un irrumpir, interrumpir y disolverse luego" (DELGADO, 1999, p.36).

Nada mais condizente à crônica do que a ideia de sua dissolução instantânea. Se os livros almejam a permanência, a fixação e o espaço privado da casa, a crônica consolida a supremacia do que é volátil, móvel e público, tal qual a marcha incessante dos pedestres de uma cidade. Além disso, ela própria é esse espaço itinerante, uma vez que liga a literatura central, canônica, à periferia marginal do jornal, metaforizando assim a definição da Escola de Chicago, recuperada por Delgado, sobre zona de transição, que nada mais é do que um passeio que liga o distrito central às zonas habitacionais periféricas. Por essa via de passagem, por esse "espaço-trânsito", parafraseando ainda Delgado a respeito da rua, transitam tipos que fortuitamente se reconhecem e se estranham e que seguem sua marcha sem se fixar. As notícias que nela se imprimem também não têm a pretensão da durabilidade, sendo descartadas por uma outra novidade a cada nova edição do jornal, daí a constatação permanente de uma transitoriedade que permeia o tempo e contamina seres e coisas. O tempo do jornal, esvaziado da eternidade que era conferida ao livro, é cada vez mais constituído de intensidades luminosas, mas que já nascem com a marca do que não dura.

Esse sentido fora captado por Machado de Assis na pergunta de caráter benjaminiano que lançou em crônica de 1886: "Mas o que é que dura neste mundo, a não ser as Pirâmides do Egito e a boa fé da minha comadre?" (PAIVA DE LUCA, 1998, p.334-335). A crônica versa sobre os desfalques que começam a se alastrar pela cidade do Rio de Janeiro, um assunto que não duraria muito, talvez "algumas horas, dois ou três dias", "mas o que é que dura mesmo neste mundo?” - pergunta o narrador. De fato, num mundo recheado de informações cotidianas, nada mais é durável para além de alguns instantes. E, embora tal fragmento, em seu questionamento filosófico, 
pareça queixar-se da transitoriedade de tudo, a ironia contida nele revela o contrário. $\mathrm{O}$ cronista parece estar à vontade, rindo-se da caducidade que paira sobre a época. Mas, enquanto ri, denuncia-a. Transita, como sempre, tal qual o personagem Brás Cubas, de Memórias Póstumas, "entre a pena da galhofa e a tinta da melancolia" (ASSIS, 1992). Nesse lugar de passagem, esvazia a imortalidade do tempo para apostar na sua repetição e decadência.

A mesma transitoriedade está presente no jornal. Osman Lins tem uma metáfora interessante para denotar a passagem do livro ao jornal. Compara-os a duas moradas distintas. A primeira procura "isolar do século as coisas permanentes ou aquelas para as quais desejaria o homem uma vida que ultrapasse a duração da sua" (LINS, 1974, p.125). Para isso, interpõe entre a habitação e o leito da rua degraus, erige muros e jardins nos palácios, eleva o pórtico e o altar-mor das igrejas. Esses teriam a mesma função que tem nos livros a encadernação em couro com guarnições de ferro, de ouro, de prata, de marfim, com fechaduras e correntes que assegurariam a condição de um espaço privilegiado, fora da ação do tempo. Sem falar na "gradação quase ritualística" que as várias sedimentações de um livro impõem: a capa, a guarda branca, a falsa folha de rosto, a verdadeira folha de rosto... Já o periódico preocupa-se com o temporário, e o assunto de capa de qualquer jornal ou revista esforça-se para perseguir o já:

Assim é que o jornal, por sua natureza ligado ao dia a dia, expressão do fato em andamento ou apenas consumado e prestes a ser esquecido, substituído, dispensa toda espécie de separação entre o texto impresso e o mundo. Reflexo do transitório, ele mesmo exemplo das coisas que não permanecem, não tem integridade alguma a resguardar. Ligado 
estreitamente ao tempo, sobrevém para fugir, passar, ser esquecido (LINS, 1974, p.126).

Mas, paradoxalmente, esse corpo que nasceu para ser esquecido eterniza a experiência de ruptura que uma multidão urbana teve ao se desalojar da morada do livro. Uma morada que prometia a continuidade de uma tradição, embalada por ideais burgueses de distanciamento, individualidade e permanência. Uma morada cujo interior dificilmente comportaria aquela que Walter Benjamin (1994) chamaria de "massa". Desalojada de tal morada, o interesse dessa massa urbana encontraria respaldo no corpo similar ao seu do jornal. Entre o individual e o coletivo, entre a permanência e o que não dura, entre o que está distante e bem guardado e o que está próximo e enxovalhado, entre o que tem casa e o que habita as ruas, ambos (massa e jornal) inclinar-se-iam para os segundos elementos dessas dicotomias.

E como se viu, a crônica é esta zona de passagem. $\mathrm{O}$ cronista é o flâneur que habita/desabita a cidade ao percorrê-la a pé, atento ao ir e vir do fluxo humano e das informações. Ele se apropria não tanto da cidade em si, mas de suas zonas itinerantes, constituindo a metáfora eficaz do que Delgado pleiteia para o estudo da antropologia urbana quando diz que ela deveria se debruçar menos sobre a cidade e mais sobre os espaços usados transitoriamente, sejam públicos (ruas, vestíbulos, parques, metrô), sejam semipúblicos (cafés, bares, discotecas, superfícies comerciais).

Es ahí donde podemos ver producirse la epifanía de lo que se há definido como especificamente urbano: lo inopinado, lo imprevisto, lo sorprendente, lo oscilante... La urbanidade consiste en esa reunión de extraños, unidos por la evitación, el anonimato y otras películas protectoras, 
expuestos a la intempérie, y al mismo tiempo, a cubierto, camuflados, mimetizados, invisibles (DELGADO, 1999, p.33).

Neste sentido, o usuário do espaço urbano é quase sempre um transeunte, alguém que está ali apenas de passagem.

Uma embriaguez acomete aquele que longamente vagou sem rumo pelas ruas. A cada passo, o andar ganha uma potência crescente; sempre menor se torna a sedução das lojas, dos bistrôs, das mulheres sorridentes, e sempre mais irresistível o magnetismo da próxima esquina, de uma massa de folhas distantes, de um nome de rua (BENJAMIN, 1994, p.186).

A descrição acima cabe ao flâneur, tipo surgido na Paris do início do século XIX e analisado por Benjamin que o aproximaria do jornalista. "A base social da flânerie é o jornalismo. É como flâneur que o literato se dirige ao mercado para se vender" (BENJAMIN, 1994, p.225). Sua força de trabalho é o tempo que gasta na contemplação dos bulevares. As novas experiências na cidade são a sua matéria-prima. $\mathrm{O}$ espetáculo da cidade o inebria e converte-se em mercadoria para consumo desta massa através das páginas volantes do jornal,

O mundo urbano tem características e particularidades que se expressam no jornalismo. Quando Georg Simmel (1979) cita o anonimato, as relações transitórias e a superficialidade como aspectos dos indivíduos urbanos, não se pode deixar de associar essas características ao jornalista. $\mathrm{O}$ jornalista experimentará no seu cotidiano a cidade como espaço da diversidade, do cruzamento de mundos e "tribos" 
diferentes, desvendando territórios heterogêneos e construindo, assim, um mapa, para muitos habitantes, desconhecido. (TRAVANCAS, 2010, p.123).

Para João do Rio, talvez o primeiro jornalista da história brasileira porque ao contrário dos outros cronistas do seu tempo imergiu no bojo das ruas para extrair material para seus textos, o flâneur (também chamado por ele de "pedestre da poesia da observação") é um ingênuo porque, "conhecendo cada rua, cada beco, cada viela, sabendo-lhe um pedaço da história, (...), acaba com a vaga idéia de que todo o espetáculo da cidade foi feito especialmente para seu gozo próprio" (RIO, 2011, p.32). E completa: "Eu fui um pouco esse tipo complexo, e, talvez por isso, cada rua é para mim um ser vivo e imóvel” (RIO, 2011, p.33).

Se para Delgado (1999), os protagonistas da antropologia urbana não poderiam ser comunidades coerentes e homogêneas e sim os atores de uma alteridade que se generaliza (passantes a deriva estrangeiros, trabalhadores e moradores das vias públicas, dissimuladores natos, peregrinos eventuais, etc.), diríamos de João do Rio que fazia a seu modo uma antropologia da cidade. Nas suas crônicas de amor às ruas todo um documento emblemático destes tipos que transitam no seio de uma cidade que enquanto cresce se torna "arruada": o cigano, o trapeiro, o apanha-rótulos, o selista, o caçador, o ledor, o tatuador, o vendedor de orações, o mercador de livro, o pintor da cidade, o velho cocheiro... Exemplos do que João do Rio chamaria de "pequenas profissões ignoradas":

Oh! Essas pequenas profissões ignoradas, que são partes integrantes do mecanismo das grandes cidades!

O Rio pode conhecer muito bem a vida do burguês de Londres, as peças de Paris, a geografia da 
Manchúria e o patriotismo japonês. A apostar, porém, que não conhece nem a sua própria planta, nem a vida de toda essa sociedade, de todos esses meios estranhos e exóticos, de todas as profissões que constituem o progresso, a dor, a miséria da vasta Babel que se transforma. (RIO, 2011, p.60).

Tais tipos são como o cronista que extrai das ruas (e devolve a elas) o insumo de seu ofício. $\mathrm{O}$ ir e vir despretensioso dos passos do flâneur/cronista que vagueia pelos espaços em movimento da cidade imprime-se no modo como executa a crônica: pouca coisa sobrevive sob as ruínas produzidas por uma cidade que se industrializa. Sempre há uma novidade, uma nova moda, a disputar o olhar de quem vagueia desinteressado, seja ele cronista ou leitor. Não é à toa que Raul Antelo vê familiaridade entre a crônica e a modernidade justamente por ambas sucumbirem à moda:

Ambas são sensíveis à circunstância repentina, ao que surge sem regras e com urgência. Ambas, porém, correm o risco de anulação na moda, explosão do acontecimento que perde seu modo na medida em que acontece, passando a ser mera informação, copiada, reproduzida, gasta. (ANTELO, 1989, p.38).

Em que pese o caráter paradoxal da crônica que usa em sua estrutura e assuntos o movimento apenas para produzir inércia, ela documenta o instante pioneiro em que a utopia de imortalidade e centralidade do livro também não dava mais conta de uma massa urbana em profunda transformação. A crônica registra o momento em que o indivíduo abandona o lugar central da casa (seja ela a casa da palavra que é o livro ou a casa real) para aventurar-se, enquanto massa, no "olho da rua", representado aqui pelo jornal. E se "la antropología urbana debería presentarse entonces más bien como una 
antropologia de lo que define la urbanidad como forma de vida" (DELGADO, 1999, p.26), a crônica representa a cidade e suas ruas menos em seu traçado espacial e mais na alma que se desprega de seus transeuntes.

E “o que é a rua?”, perguntar-se-ia João do Rio que teria consultado vários dicionários na busca por uma definição. Para tais dicionários, a rua era "apenas um alinhado de fachadas por onde se anda nas povoações. Ora a rua é mais do que isso, a rua é um fator da vida nas cidades, a rua tem alma!" (RIO, 2011, p.29). "As ruas são a morada do coletivo", diria Benjamin (1994, p.194), para quem "a rua conduz o flanador a um tempo desaparecido" (1994, p.185), tempo da infância.

A crônica documenta, então, o significado e a essência da rua na modernidade. No descompasso das passadas do transeunte/ cronista moderno que, distraído, vive a dialética própria dos períodos de transição, a representação de uma antropologia urbana que pouco tem a ver com os centros fixos, domesticados e estáveis.

Si la antropologia urbana quiere serlo de veras, debe admitir que todos sus objetos potenciales están enredados en una tupida red de fluidos que se fusionan y licúan o que se fisionan y se escinden, un espacio de dispersiones, de las intermitências y de los encabalgamientos entre identidades. (DELGADO, 1999, p.45).

O mesmo caráter de dispersão e circulação encontra-se na crônica. Contra a rigidez e durabilidade da literatura canônica, debruça-se sobre o movimento e as histórias mínimas que se processam nas ruas da grande cidade. E, ao fazê-lo, perfaz um movimento similar ao que Rocha e Eckert reivindicam para a antropologia urbana: o deslocamento do "foco de análise da descrição realista da 
cidade na história para um conhecimento compreensivo da cidade segundo os acontecimentos anódinos que ocorrem no seu interior e a efervescência que rege a vida ordinária de seus habitantes" (ROCHA; ECKERT, 2005, p.95). Ou nas palavras do personagem Brás Cubas:

Quem não sabe que ao pé de cada bandeira grande, pública, ostensiva, há muitas vezes várias outras bandeiras modestamente particulares, que se hasteiam e flutuam à sombra daquela, e não poucas vezes lhe sobrevivem? Mal comparando, é como a arraia-miúda, que se acolhia à sombra do castelo feudal; caiu este e a arraia ficou. (MACHADO DE ASSIS, 1992, p.23).

Por sua natureza miúda, a crônica assume um lugar estratégico para a reflexão antropológica.

Nas grandes metrópoles, a vida humana torna-se objeto principal de estudo pelos "retalhos, os resíduos", "secundário ou excêntrico": a moda, o jogo, o colecionador, os dioramas, a prostituição, o flâneur, as passagens, o interior, as ruas, a fotografia, o réclame. (ROCHA; ECKERT, 2005, p.83, grifos do autor).

A crônica é, sem dúvida, um destes resíduos.

\section{Conclusão}

Neste artigo, procuramos derivar do residual da crônica um registro do instante pioneiro em que a experiência do urbano passou a ser tematizada e vivenciada pelo jornalista/habitante da 
cidade moderna. Para tanto, procuramos definir o gênero, buscando suas características e origens, muito embora a imprecisão e a indefinição - tanto no que diz respeito a seu nascimento quanto a sua forma - sejam suas marcas por excelência.

A partir da análise de algumas crônicas produzidas pelos primeiros jornalistas brasileiros, na virada do século XIX para o XX, especificamente no Rio de Janeiro - cidade que traduz todo o imaginário da época e que ditava modas e costumes - deriva-se uma experiência pioneira na relação com as ruas, seus modos de vivência e comportamentos urbanos, capaz de dialogar com a teoria produzida por Walter Benjamin no contexto europeu. Demonstramos que, na Paris do século XIX, já havia uma demanda por uma narrativa que perfilasse os transeuntes de uma cidade em vias de modernização e que aplacasse o medo de se ir às ruas e exaltasse o fascínio de aventurar-se na multidão. Adotamos aqui a perspectiva do filósofo alemão que consiste em tomar a realidade por algo descontínuo, misturando os tempos, entrelaçando as várias histórias, dissolvendo o centro, preferindo as bordas, as margens, os produtos menores.

A interface entre a Antropologia, a Comunicação e a Literatura enfatiza problemáticas também fronteiriças: a ocupação da cidade, o espaço intermediário das galerias, o texto intermediário entre o livro e o jornal (a crônica), o ofício intermediário entre o literato e o jornalista (o cronista), entre outras.

A imersão em algumas crônicas do período recortado (finais do século XIX, começos do XX) revela assuntos pertinentes ao entendimento do significado do urbano no contexto moderno, tais como o encantamento pelas ruas, traduzido na descrição panorâmica de seus espaços, na fisiologia de seus habitantes, no fluxo de informações que as ruas fornecem. Por fim, derivam-se daí cruzamentos 
entre a teoria e os produtos textuais selecionados e discute-se a figura do jornalista-flâneur na sua especificidade pioneira.

Porque é da experiência de passagem do grande literato para o pequeno (miúdo) cronista das ruas que se extrai a filosofia (não total, porém ambígua e aberta) dos tempos. E, para isso, o papel da crônica, essa cultura marginal diante da Cultura, adquire importância decisiva. A crônica, por ser uma estrutura que não faz parte da escritura canônica, talvez documente melhor o movimento impreciso da história (assim como Benjamin optou pelo drama barroco alemão do século XVII, e não pela forma mais bem acabada de drama - o espanhol - porque da sua imprecisão e da sua exclusão do sentido tradicional de belo é que poderia ser derivada a imperfeição de uma história que se queria linear e contínua).

Afinal, na perspectiva benjaminiana, são as formas abandonadas, não muito lembradas pela historiografia oficial, que revelam a verdadeira história se representando. Ou nas palavras de Machado de Assis (1998, p. 336), em crônica do dia 22 de março de 1886, da Gazeta de Notícias: "A história estuda-se em documentos assim, não preparados, mas ingênuos e sinceros; é deles que se pode sacar a vida e a fisionomia de um tempo".

\section{Referências}

ANTELO, Raúl. João do Rio: o dândi e a especulação. Rio de Janeiro: Taurus-Timbre, 1989.

BENJAMIN, Walter. Charles Baudelaire: um lírico no auge do capitalismo. Tradução de José Carlos Martins Barbosa e Hemerson Alves Baptista. 3.ed. São Paulo: Brasiliense, 1994. 
CANDIDO, Antonio. A vida ao rés-do-chão. In: . et al. A crônica: o gênero, sua fixação e suas transformações no Brasil. 108 Campinas; Rio de Janeiro: Ed. da UNICAMP/Fundação Casa de Rui Barbosa, 1992.

DAMATTA, Roberto. A casa e a rua: espaço, cidadania, mulher e morte no Brasil. Rio de Janeiro: Guanabara, 1987.

DELGADO, Manuel. El animal público: hacia una antropologia de los espacios urbanos. Barcelona: Anagrama, 1999

FOLHA DE S. PAULO (Org.). Machado de Assis: crônicas escolhidas. São Paulo: Ática, 1994.

LINS, Osman. Guerra sem testemunhas: o escritor, sua condição e a realidade social. São Paulo: Ática, 1974. (Coleção ensaios, v. 2).

MACHADO DE ASSIS. Memórias póstumas de Brás Cubas. 3.ed. São Paulo: FTD, 1992.

MEYER, Marlyse. Voláteis e versáteis. De variedades e folhetins se faz a chronica. In: CANDIDO, Antonio... et al. A crônica: o gênero, sua fixação e suas transformações no Brasil. São Paulo: Editora da UNICAMP; Rio de Janeiro: Fundação Casa Rui Barbosa, 1992. p. 93-133.

PAIVA DE LUCA, Heloisa Helena (org.). Balas de estalo de Machado de Assis. São Paulo: Annablume, 1998.

RIO, João do. A alma encantadora das ruas: crônicas. 5. reimpr. São Paulo: Companhia de Bolso, 2011 
ROCHA, Ana Luiza Carvalho da; ECKERT, Cornélia. O tempo e a cidade. Porto Alegre: Editora da UFRGS, 2005.

TRAVANCAS, Isabel Siqueira. O mundo dos jornalistas. 4.ed. São Paulo: Summus, 2011. 